\title{
Role of Personality Characteristics and Sexual Orientation in the Risk for Sexual Addiction Among Israeli Men: Validation of a Hebrew Sex Addiction Scale
}

\author{
Guy Paz ${ }^{1} \cdot$ Mark D. Griffiths $^{2}$ (D) $\cdot$ Zsolt Demetrovics $^{1} \cdot$ Attila Szabo $^{1,3}$
}

Published online: 22July 2019

(C) The Author(s) 2019

\begin{abstract}
Men having sex with men are known to exhibit heightened sexual activity. This raises the conjecture that different sexual orientations exhibit different levels of sex addiction risk, which is also affected by personality. The present study examined the prevalence of the sex addiction risk within the context of sexual orientation and personality in Israeli men while also validating the Hebrew Bergen-Yale Sex Addiction Scale (HBYSAS). Results based on 177 participants showed that the HBYSAS is appropriate for assessing the risk for sex addiction in Israeli men. Furthermore, results showed that sex addiction risk varied with individuals' sexual orientation while being modestly associated with higher neuroticism and lower conscientiousness.
\end{abstract}

Keywords Sex addiction · Hypersexual behavior · Bergen-Yale Sex Addiction Scale · Addiction personality $\cdot$ Israeli sexual behavior

Sexual health, as defined by the World Health Organization (WHO 2018), is the achievement of physical, emotional, psychological, and social wellbeing in relation to an individual's sexuality (WHO 2018). Excessive sexual behavior has a long history of being a controversial topic that is poorly understood (Rinehart and McCabe 1997). Such behavior has historically been referred to as satyriasis (in men), nymphomania (in women), erotomania, Casanova Syndrome (in men), and Don Juan Syndrome (in men) and more recently has been labeled as

Mark D. Griffiths

mark.griffiths@ntu.ac.uk

1 Institute of Psychology, ELTE Eötvös Loránd University, Budapest, Hungary

2 Department of Psychology, The Nottingham Trent University, 50 Shakespeare Street, Nottingham NG1 4FQ, UK

3 Institute of Health Promotion and Sport Sciences, ELTE Eötvös Loránd University, Budapest, Hungary 
hypereroticism, hyperlibido, oversexuality, hyperactive sexuality, and hypersexual behavior (Orford 2001; Rinehart and McCabe 1997).

Over the years, excessive sexual behavior has negatively affected millions of people. It is estimated that 9 to 37 million Americans (3-8\%) are addicted to sex and/or pornography (Barrilleaux 2016; Sussman et al. 2011; Wilcox 2015). The consequences of sex addiction typically include depression, self-loathing, shame, despair, anxiety, isolation and loneliness, sexually transmitted diseases, violent behavior, legal problems, loss of family, employment, status, self-respect, and self-esteem (Barrilleaux 2016; Chatzittofis et al. 2017; Dhuffar and Griffiths 2015). Consequently, some authors describe sex addiction/hypersexual disorder as a debilitating problem which may include impairment to physical health functioning, cognition, impulse control, attachment, intimacy, and mood (Karim and Chaudhri 2012).

Defining sexual addiction appears to be challenging because there is no general consensus concerning the terminology, characteristics, and treatment of the behavioral addictions associated with sexuality (Barrilleaux 2016). To date, the concept of problematic or out of control sexual behaviors is simultaneously referred to as "sexual addiction," "sexual impulsivity," "hypersexuality," "compulsive sexual behavior," "impulsive/compulsive sexual behavior," and "dysregulated sexuality" (Joannides 2012). Wilcox (2015) defined sex addiction as "a pattern of unwanted sexual behavior that is acted out despite increasingly negative effects and attempts to stop" (page 8). Kafka (2013) proposed the term "hypersexual disorder" to be included within the most recent (fifth) edition of the Diagnostic and Statistical Manual of Mental Disorders (DSM-5) and delineated the inclusion criteria (i.e., multiple descriptive behavioral symptoms, significant personal distress and/or social role impairment, exclusion criteria, and minimum age requirement). Likewise, similar concepts regarding problematic sexual behaviors such as compulsive sexual behavior (CSB) have been proposed to be included in the ICD-11 (Gola and Potenza 2018).

A recent study defined sex addiction as being intensely involved with sexual activities (such as having sexual fantasies, masturbation, sexual intercourse, pornography consumption) across a vast array of media with reportedly uncontrollable sexual motivation, time consumption, and engagement in sexual activity that has negative impact on various aspects of an individual's life (Andreassen et al. 2018). Andreassen et al. (2018) argued that sexual addiction may be best understood under the well-established "components model" of addiction (Griffiths 2005). The model is based on six typical behavioral aspects of addictions: salience, mood modification, tolerance, withdrawal, conflict, and relapse (Griffiths 1996, 2005). There are several forms of behavioral addiction that have been empirically (and widely) investigated including gambling, gaming, eating, sex, shopping, exercising, and working (Griffiths 2005; Karim and Chaudhri 2012).

Applying the addiction components model, Andreassen et al. (2018) developed and validated the Bergen-Yale Sex Addiction Scale (BYSAS) using a Norwegian sample. The authors also found a relationship between personality traits and sex addiction in both men and women. For example, high levels of sex addiction were positively related to greater extroversion and neuroticism, while being inversely related to conscientiousness (Andreassen et al. 2018).

An association between an individual's personality traits and the increased likelihood of risky behavior is consistently reported in the literature (Mcghee et al. 2012; Raynor and Levine 2009; Terracciano and Costa 2004; Terracciano et al. 2008). Studies show that individuals addicted to substances and behaviors exhibit significantly higher impulsivity and neuroticism than non-addicted controls (Zilberman et al. 2018). When comparing an array of different behavioral and substance addictions, Zilberman et al. (2018) found that individuals with drug 
use disorders and compulsive behaviors had similar profiles and scored low in traits of agreeableness and conscientiousness. Also, neuroticism was found to be positively related to both substance and behavioral addictions including internet addiction, online gaming addiction, and smartphone addiction, which when combined could lead to depression and consequently decreasing an individual's quality of life (Gao et al. 2017; Kayiș et al. 2016; Mehroof and Griffiths 2010).

Epidemiological findings have consistently found that sexual addiction and hypersexuality are more prevalent among men than women (Barrilleaux 2016; Karila et al. 2014; Karim and Chaudhri 2012; Wilcox 2015). For both genders, the use of internet can play a key role in maintaining their sexual addiction (Dhuffar and Griffiths 2015) where women engage in socially oriented behaviors (i.e., chat rooms) whereas men prefer to engage in masturbation while visiting pornographic websites (Barrilleaux 2016; Green et al. 2012). Men also account for up to $95 \%$ of all paraphilias practiced. However, these behaviors tend to occur among heterosexual men and are much less prevalent in gay men (Birchard 2011).

It has been suggested in the literature that gay/bisexual men are more prone to report symptoms of hypersexuality and sexual compulsivity than heterosexual men. Research has characterized "men who have sex with men" (MSM) as more sexually active than others with the highest lifetime number of sex partners, and a younger reported median age of first sexual activity (Bőthe et al. 2018; Glick et al. 2012; Levin et al. 2009). Studies examining sexual compulsivity among MSM demonstrate a higher prevalence of highly sexually compulsive individuals (approximately 30\%) than in the general population (3-6\%) (Grov et al. 2010; Rooney et al. 2018). When trying to assess the origins of sexual compulsivity among MSM, bisexual and gay males have articulated both intrinsic and extrinsic sources such as belief in predisposition, emotional neglect, and sexual abuse, alongside availability and accessibility of sexual partners (Parsons et al. 2008). When comparing gay men to lesbian women, gay men exhibit significantly greater symptoms of sexual compulsivity (Böthe et al. 2018; Missildine et al. 2005). However, MSM appear to show higher compliance in protected sexual encounters, specifically with higher use of condoms in anal sexual intercourse than heterosexuals tend to use in vaginal intercourse (Glick et al. 2012).

Hypersexuality, sexual compulsion, and sexual addiction have consistently been associated with neuroticism and anxiety (Kayiș et al. 2016; Pinto et al. 2013; Raviv 1993). A recent study compared a wide array of sexual orientations within men (men who are attracted only to women, predominantly attracted to women, attracted to both men and women, predominantly attracted to men, and those attracted solely to men) and found that neuroticism-anxiety appeared to increase as one's same-sex orientation becomes more exclusive (Wang et al. 2014). Furthermore, Wang et al. (2014) found that when gay and bisexual men are grouped together, their assessed neuroticism is a full standard deviation above those grouped as heterosexuals.

To date, very few studies have examined the difference in sexual addiction risk between the sexual orientations within MSM and between heterosexual males. To our knowledge, research in the field of sexual addiction tends to either study MSM exclusively, or in comparison to women and/or other demographics within the LGBTQ (lesbian, gay, bisexual, transgender, and queer) communities (Bőthe et al. 2018; Grov et al. 2010; Kelly et al. 2009; Wang et al. 2014). However, a recent study found heterosexual, bisexual, and gay men and women reported differences in cybersex behavior and as such, the present study investigates the difference in risk of acquiring a sexual addiction across sexual orientations within men (Green et al. 2012).

Today, prejudice and discrimination against gay, lesbian, and bisexual individuals is considered to be widespread (Butler 2000; Herek and Garnets 2007). Studies indicate how 
social stressors, such as prejudice and discrimination, may influence some forms of mental disorders such as affective, anxiety, and substance abuse disorders (Cochran et al. 2003). Consequently, studying the mental health of minority communities, such as LGBTQ communities, carries a risk of further stigmatizing this group as non-heterosexuals (Herek and Garnets 2007). The importance of gathering information that aims to better understand and promote the wellbeing of a marginalized minority group is considered by the present authors as outweighing the inherent risk of unintentional stigmatization by means of referral to the LGBTQ group. Thus, it is crucial for any study in the field to proceed cautiously when studying a sensitive topic such as risk of sexual addiction in the LGBTQ community.

In recent years, most men with newly diagnosed HIV infection in Israel (where the present study was carried out) were predominantly MSM (Levy et al. 2011). As aforementioned, compulsive sexual behavior has been found to be associated with greater probability of engaging in unprotected sexual intercourse and increases an individual's likelihood in contracting sexually transmitted diseases (Barrilleaux 2016; Coleman et al. 2010). Therefore, the present authors believe it is important to explore whether the risk of acquiring a sexual addiction is stable across sexual orientations versus the established difference between sexual behaviors (MSM versus MSW).

The present study explores the relationships between personality, sexual orientation, and risk for sexual addiction specifically among Israeli men, rather than across all sexes. The aim was to extend Andreassen et al.'s (2018) study to Israeli men by assessing the relationship between personality traits and the risk of sexual addiction, as well as extending their work by determining whether the risk for sexual addiction is associated with sexual orientation. Given that the present study was conducted with Israeli men, the instrument developed by Andreassen et al. (2018), the BYSAS, had to be translated and validated in Hebrew, serving another objective of the study. Additionally, two hypotheses were tested in the present study: (i) neuroticism would be positively related and conscientiousness would be negatively related to the risk of sexual addiction, and (ii) the risk for sexual addiction, as based on BYSAS scores, would differ among heterosexuals, bisexuals, and gay men. The study presumes neuroticism and conscientiousness to be related to an individual's risk of sexual addiction in the Israeli male population as found by Andreassen et al. (2018) in their Norwegian sample. Secondly, due to recent findings in differences across sexual orientations in cybersex behavior and neuroticism- anxiety traits, the study expected to find a difference across sexual orientations and risk of sexual addiction and is considered exploratory (Green et al. 2012; Wang et al. 2014).

\section{Methods}

\section{Participants}

Participants were recruited via a Hebrew advertisement in non-specialized, general social media groups via Facebook. The invitation called for Israeli males to participate in a study of sexual behavior and personality characteristics. Of the 254 Israeli respondents who began responding to an online survey, 177 fully completed all the questions (30\% loss). The sample comprised solely of men. Of these, 113 identified themselves as heterosexuals (63.8\%), 48 as gay men $(27.1 \%)$, and the remaining 16 as bisexuals (9\%). The participants' mean age was 32.44 years $(S D=8.41)$, ranging from 19 to 70 years with approximately three-fifths of the 
sample being married or in a relationship (58.2\%). The mean number of years' education was 15.33 years $(S D=3.11)$ with 52 completing High School $(29.4 \%), 55$ completing a Bachelor's degree $(31.1 \%), 41$ completing a Master's degree (23.2\%), and the remainder completing a $\mathrm{PhD}$ or higher qualification. Nearly one-third of the sample $(30.5 \%)$ were participants who reported a monthly income below the country's average of 10,884 New Israeli Shekels; (Statistics 2018).

The study was approved by the research team's Research Ethics Committee of the Faculty of Education and Psychology at a large urban university. The committee's criteria of evaluation fully adhered to the international ethical guidelines and regulations for research with human participants, in accordance with Helsinki Declaration (Rickham 1964) and the American Psychological Association 2002, (Ethical Principles of Psychologists and Code of Conduct 2002).

\section{Measures}

All measures were in Hebrew and designated for Israeli individuals fluent in the Hebrew language. First, participants answered demographic questions concerning age, relationship status, highest completed education, average monthly income, and their sexual orientation.

The Five-Factor Model of personality (commonly referred to as the "Big Five"). In the present study, the Mini-International Personality Item Pool (Mini-IPIP; Donnellan et al. 2006) was used to assess the participant's personality in accordance with the Big Five Factors Theory (McCrae 1990; McCrae and Costa 1999; McCrae and John 1992). The measure was translated by the authors and largely based upon the Hebrew translated 180-item version of the IPIP NEO scale (Oreg and Sverdlik 2014). The instrument was translated using a standardized backtranslation procedure using two independent scholars fluent in both languages (Beaton et al. 2000). The Mini-IPIP is a 20-item, 5-point Likert scale (ranging from $1=$ very inaccurate to $5=$ very accurate). The 20 items are divided into five subscales: extroversion (e.g. "I am the life of the party"; $\mathrm{M}=12.05, \mathrm{SD}=3.791$, Cronbach's $\alpha=0.756$ ), conscientiousness (e.g. "I like order"; $\mathrm{M}=13.53, \mathrm{SD}=3.703$, Cronbach's $\alpha=0.710$ ), neuroticism (e.g. "I get upset easily"; $\mathrm{M}=10.65, \mathrm{SD}=3.528$, Cronbach's $\alpha=0.664$ ), agreeableness (e.g. "I sympathize with others' feelings"; $\mathrm{M}=16.18, \mathrm{SD}=3.434$, Cronbach's $\alpha=0.863$ ), and intellect/imagination which is closely related to openness (e.g. "I have a vivid imagination"; $\mathrm{M}=16.16, \mathrm{SD}=$ 3.063, Cronbach's $\alpha=0.714$ ).

Bergen-Yale Sex Addiction Scale The Bergen-Yale Sex Addiction Scale (BYSAS) is a recently developed tool that utilizes the six components of addiction proposed by Griffiths (2005) in his theoretical framework of addiction. The component criteria in the BYSAS assesses: salience (preoccupation with sex/masturbation), mood modification (sex/masturbation improves mood), tolerance (increasing amount of sex/masturbation is required in order to be satisfied), withdrawal symptoms (reduction or preclusion from sex/masturbation creates restlessness and negative feelings), conflict (sex/masturbation creates conflicts and causes problems for the individual), and relapse/loss of control (return to old sex/masturbation patterns after a period of control or absence). The scale assesses sexual behaviors and cognitions during the past year using a five-point Likert response format $(0=$ very rarely to $4=$ very often) with participants' total score ranging between 0 and 24 (Appendix). Example items include "spent a lot of time thinking about sex/masturbation or planned sex" or "became restless or troubled if you have been prohibited from sex/masturbation". The original BYSAS 
presented with good psychometric properties (Andreassen et al. 2018). The validation of the Hebrew BYSAS (HBYSAS) is presented in the "Results" section below.

The HBYSAS's continuous scores were categorized into four risk groups of sexual addiction. The categorization is based on Andreassen et al. (2018) and the comparable cutoff points of behavioral addictions questionnaires such as GAD (Game Addiction Scale) (Lemmens et al. 2009). Participants who scored a total HBYSAS score of 0 were categorized as "no risk of sex addiction." Participants who scored between 1 and 6 were categorized as "low risk of sex addiction." Participants who scored 7 to 17 were categorized as "moderate risk for sex addiction." Finally, individuals who scored 18 or above were classified as being at "high risk of sexual addiction." In addition to basing the study's categorization method on prior literature, the study operationalized a participant's mean response of "often" on the presented items as an appropriate threshold for the classification of high risk of sexual addiction. The study's rationale is based upon Lemmens et al.'s (2009) comparison between monothetic and polythetic format's threshold for addiction, advocating for monothetic format as a more stringent tool for assessment.

\section{Procedure}

The call for participants on various social media clearly indicated that the study was designated for males only. All respondents had to confirm being at least 18 years of age. The surveys were completed via the Qualtrics research platform (Qualtrics 2005). Participation in the study was voluntary and fully anonymous.

\section{Data Analysis}

The data were analyzed with SPSS version 25.0 (IBM Corporation 2017b) while the confirmatory factors analysis of the BYSAS was performed with Amos version 25.0 (IBM Corporation 2017a). Risk of sexual addiction was computed according to the proposed risk categories (Andreassen et al. 2018). An individual's personality trait relations with the categorical BYSAS risk group were assessed by first using Spearman's correlation and then followed up using a multinomial logistic regression to assess the effect of personality upon BYSAS categories' variance. Finally, Fisher's exact test was used to test the hypothesis that the risk of sexual addiction differed among individuals with different sexual orientations.

\section{Results}

\section{Validation of the BYSAS into Hebrew (HBYSAS)}

Initially, the factorability of the six BYSAS items was examined on approximately half of the sample $(n=85)$. All six items correlated at least 0.30 with at least one other item, suggesting reasonable factorability. The Kaiser-Meyer-Olkin (KMO) measure of sampling adequacy was 0.803 , which is higher than the commonly recommended value of 0.6 , and Bartlett's test of sphericity was statistically significant $\left(\chi^{2}[15]=133.60, p<0.001\right)$. The anti-image correlations were all over 0.70 . Finally, the commonalities were above 0.4 except for one item $(0.387$; Item 6). A principal component analysis (PCA) without rotation was used because the initial purpose was to compute the composite score for the components underlying the short version 
of the HBYSAS. One eigenvalue above 1 (2.97) and the scree-plot identified a single component that explained $49.44 \%$ of the variance. All factor loadings were above 0.6 . The internal reliability of the HBYSAS was acceptable (Cronbach's $\alpha=0.79$ ).

A confirmatory factor analysis (CFA) was performed with the remainder of the sample $(n=92)$. Initially, the fit indices were relatively poor, but after examining the modification indices, high covariances between three pairs (Items 1 and 4, 3 and 4, and 4 and 5) were noted, which were subsequently considered in the model. Accordingly, the CFA was re-analyzed with the covariances in the model. The emerging results yielded good model fit indices $\left(\chi^{2}[6]=6.28, p=0.393\right.$; $\mathrm{CMIN} / \mathrm{DF}=1.047$; $\mathrm{SRMR}=0.0476 ; \mathrm{CFI}=0.998 ; \mathrm{GFI}=0.978 ; \mathrm{TLI}=0.995)$, and $\mathrm{RMSEA}=$ $0.023(0.000-0.140)$. Consequently, based on the CFA and the PCA performed on the two halves of the sample, the HBYSAS appears to be a valid and reliable tool for assessing the risk for sexual addiction in the Israeli men and, therefore, for testing the research hypotheses. The present study found $3.9 \%$ of the Israeli male participants were classed as being at high risk for sexual addiction because they equaled or exceeded the cut-off score of 18 on the HBYSAS.

\section{The Five-Factor Model of Personality and the Bergen-Yale Sex Addiction Scale}

First, to explore the relationship between the HBYSAS categories and the five-factor model (FFM) personality traits, Spearman's nonparametric correlations were performed. Neuroticism was weakly but directly related to the HBYSAS risk categories with $\rho(177)=.173(p=0.02)$ while conscientiousness was weakly but inversely related to the HBYSAS risk categories with $\rho(176)=-0.152(p=0.04)$. The complete results are outlined in Table 1.

A multinomial logistic regression was then conducted to understand the contribution of the five personality variables in explaining the BYSAS risk categories, in accord with Andreassen et al. (2018). The explanatory variables did not improve the model, given that the unexplained variation did not substantially decrease from 288,904 in the model with only a constant to 270,611 , and as such, there was no statistical significance $(p=0.248, d f=15)$.

The model appeared to fit the data with Pearson's correlation's $\chi^{2}=396.007, d f=510$, and Pearson's $p=1.00$ with a deviance of $\chi^{2}=270.611, d f=510$, and $p=1.00$. When assessing the power, or the explained variance, a very low $\beta$ with a Nagelkerke $=0.122$ was observed, meaning that personality only explained $12.2 \%$ of the variance of the HBYSAS risk groups. Of the five personality traits, only one trait appeared significant. The model indicates low conscientiousness to be significant with $p=0.016$ ( $d f=3$ and $\chi^{2}=10.263$; see Table 2$)$. Within the model itself, there appeared to be no significance in personality trait scores upon the different HBYSAS

Table 1 Spearman correlation coefficient between variables

\begin{tabular}{|c|c|c|c|c|c|}
\hline Variables & $\begin{array}{l}\text { Risk for sexual } \\
\text { addiction }\end{array}$ & Extraversion & Agreeableness & Conscientiousness & Neuroticism \\
\hline $\begin{array}{l}\text { 1. Risk for sexual } \\
\text { addiction }\end{array}$ & - & & & & \\
\hline 2. Extraversion & 0.300 & & & & \\
\hline 3. Agreeableness & -0.270 & $0.249^{* *}$ & & & \\
\hline 4. Conscientiousness & $-0.152 *$ & 0.051 & 0.026 & & \\
\hline 5. Neuroticism & $0.173 *$ & 0.039 & -0.100 & -0.103 & \\
\hline $\begin{array}{l}\text { 6. Intellect/ Imagina- } \\
\text { tion }\end{array}$ & 0.002 & 0.054 & $0.252 * *$ & -0.093 & -0.078 \\
\hline
\end{tabular}

$* p<0.05$ (two-tailed); $* * p<0.01$ (two-tailed) 
Table 2 Multinomial logistic regression of personality and risk for sexual addiction. (Reference category: BYSAS category score of $0, \mathrm{OR}=1.00, n=176$ )

\begin{tabular}{llll}
\hline & $\begin{array}{l}\text { Mild sex addiction } \\
(1 \geq \mathrm{BYSAS} \leq 6)\end{array}$ & $\begin{array}{l}\text { Moderate sex addiction } \\
(7 \geq \mathrm{BYSAS} \leq 17)\end{array}$ & $\begin{array}{l}\text { High sex addiction } \\
(\mathrm{BYSAS} \geq 18)\end{array}$ \\
\hline Independent variable & OR $(95 \% \mathrm{CI})$ & OR $(95 \% \mathrm{CI})$ & OR $(95 \% \mathrm{CI})$ \\
Extroversion & $1.166(0.585-2.324)$ & $1.209(0.608-2.405)$ & $1.086(0.532-2.218)$ \\
Agreeableness & $1.324(0.737-2.376)$ & $1.300(0.727-2.325)$ & $1.315(0.704-2.457)$ \\
Conscientiousness & $1.349(0.691-2.632)$ & $1.184(0.609-2.302)$ & $1.452(0.717-2.942)$ \\
Neuroticism & $0.814(0.446-1.484)$ & $0.880(0.484-1.600)$ & $1.002(0.528-1.899)$ \\
Intellect/Imagination & $0.655(0.240-1.792)$ & $0.655(0.240-1.786)$ & $0.631(0.224-1.773)$ \\
\hline
\end{tabular}

No significant results were found

OR odds ratio, CI confidence interval, BYSAS Bergen-Yale Sex Addiction Scale; the sample size was one less since one participant did not fill out the personality questionnaire

groups. As such, it can only be inferred from the data that within the Israeli male population personality did not play a significant role in explaining sexual addiction risk groups.

\section{Comparing Sexual Addiction Between Sexual Orientations}

In order to compare different sexual orientations' likelihood of being in a specific sexual addiction risk group, the crosstabs function in SPSS 25.0 was used and yielded a contingency table through which the between-groups proportions were compared as shown in Table 3.

Table 3 Sexual orientation and BYSAS contingency table

\begin{tabular}{|c|c|c|c|c|c|}
\hline & $\begin{array}{l}\text { No sex } \\
\text { addiction } \\
(\text { BYSAS }=0)\end{array}$ & $\begin{array}{l}\text { Mild sex addiction } \\
(1 \geq \text { BYSAS } \leq 6)\end{array}$ & $\begin{array}{l}\text { Moderate sex } \\
\text { addiction } \\
(7 \geq \text { BYSAS } \leq 17)\end{array}$ & $\begin{array}{l}\text { High sex } \\
\text { addiction } \\
(\text { BYSAS } \geq 18)\end{array}$ & Total \\
\hline Heterosexual men & 0 & 33 & 78 & 2 & 113 \\
\hline $\begin{array}{c}\% \text { within Sexual } \\
\text { orientation }\end{array}$ & $0.0 \%$ & $29.2 \%$ & $69.0 \%$ & $1.8 \%$ & $100 \%$ \\
\hline $\begin{array}{l}\text { \% within sexual } \\
\text { addiction } \\
\text { group }\end{array}$ & $0.0 \%$ & $55.9 \%$ & $71.6 \%$ & $28.6 \%$ & $63.8 \%$ \\
\hline Bisexual men & 2 & 3 & 11 & 0 & 16 \\
\hline $\begin{array}{l}\% \text { within sexual } \\
\text { orientation }\end{array}$ & $12.5 \%$ & $18.8 \%$ & $68.8 \%$ & $0.0 \%$ & $100 \%$ \\
\hline $\begin{array}{l}\% \text { within sexual } \\
\text { addiction } \\
\text { group }\end{array}$ & $100 \%$ & $5.1 \%$ & $10.1 \%$ & $0.0 \%$ & $9.0 \%$ \\
\hline Gay men & 0 & 23 & 20 & 5 & 48 \\
\hline $\begin{array}{c}\% \text { within sexual } \\
\text { orientation }\end{array}$ & $0.0 \%$ & $47.9 \%$ & $41.7 \%$ & $10.4 \%$ & $100 \%$ \\
\hline $\begin{array}{l}\% \text { within sexual } \\
\text { addiction } \\
\text { group }\end{array}$ & $0.0 \%$ & $39.0 \%$ & $18.3 \%$ & $71.4 \%$ & $27.1 \%$ \\
\hline Total & 2 & 59 & 109 & 7 & 177 \\
\hline $\begin{array}{l}\% \text { within sexual } \\
\text { orientation }\end{array}$ & $1.1 \%$ & $33.3 \%$ & $61.3 \%$ & $4.0 \%$ & $100.0 \%$ \\
\hline $\begin{array}{l}\% \text { within sexual } \\
\text { addiction } \\
\text { group }\end{array}$ & $100.0 \%$ & $100.0 \%$ & $100.0 \%$ & $100.0 \%$ & $100.0 \%$ \\
\hline
\end{tabular}


Due to the prevalence of observations within the cells of the contingency table, a Fisher's exact test was used to assess whether the relevant proportions of sexual addiction risk groups were independent of an individual's sexual orientation. Using SPSS 25.0, the Fisher's exact test score showed sexual orientation to be significant $(22.729, p<0.001)$. The contingency table shows how individuals with different sexual orientations were unevenly dispersed across sexual addiction risk groups (see Table 3). The "no sexual addiction" group was found to be solely comprised of bisexual males, while no bisexual males were found to have high risk for sexual addiction. Both the mild risk for sexual addiction and moderate risk for sexual addiction primarily comprised heterosexual males with $55.9 \%$ and $71.9 \%$, respectively. Finally, high risk for sexual addiction comprised mostly gay men (71.4\%).

The dispersion of sexual addiction risk group within the sexual orientation was also significantly different across sexual orientations. Heterosexual males ranged between mild risk of sexual addiction to high risk of sexual addiction, while most of the group were found to have moderate risk of sex addiction (69\%). Bisexual males ranged between no risk of sex addiction to moderate risk of sex addiction, with most being found to have moderate risk of sexual addiction (68.8\%). Finally, gay males ranged between mild risk of sexual addiction to high risk of sex addiction, with the majority split between mild risk of sex addiction $(47.9 \%)$ and moderate risk of sex addiction $(41.7 \%)$.

\section{Discussion}

The most important finding of the present study, which to the best of the authors' knowledge is reported for the first time in the literature, is the significant difference in the risk for sexual addiction in Israeli men with different sexual orientations. More specifically, participants who were classified as being at high risk for sexual addiction were predominantly gay men $(71.4 \%)$ while participants who did not have any risk for sexual addiction were solely bisexual men. Both heterosexual males and bisexual males showed higher proportions of mild and moderate risk for sex addiction than in the other risk groups (see Table 3). A large proportion of the sample $(61.3 \%)$ showed moderate risk of sex addiction, followed by mild risk of sex addiction $(33.3 \%)$. As such, it is crucial to interpret the results cautiously because the study may have been influenced by self-selection bias of individuals choosing to participate in the present study. The results in the present study showed no specific trend but simply differences in prevalence rates across different sexual orientations.

The results differed from earlier findings which has associated gay and bisexual males by their sexual behaviors and as such "MSM" (Grov et al. 2010; Kelly et al. 2009; Wang et al. 2014). The acronym MSM was originally coined in 1994, during the HIV epidemic and was sought to promote an epidemiological perspective and to emphasize the value of one's actions upon his health (Young and Meyer 2005). Young and Meyer (2005) indicated the shortcomings of the term and opened a discussion of the term and its alternatives. The present study's findings indicate how bisexual and gay Israeli men show different risk of sexual addiction which could not be obtained by using the participants' sexual behavior alone.

The purpose of the present study was to provide new insight and explore whether there may be a difference in an individual's risk of acquiring a sexual addiction across sexual orientations/identities in the Israeli male population. To date, the etiology of sexual addiction/hypersexuality is unknown; therefore, the ability to infer what may have produced the difference found in the study is limited (Kaplan and Krueger 2010). However, of the six 
addiction components (Griffiths 1996, 2005), addiction is described as having a mood modifying quality. Similarly, research indicates how some sexually compulsive individuals explain their behaviors due to negative affect, stress release, and a need for validation (Black et al. 1997; Parsons et al. 2008).

Studies in minority stress explain how stigma, prejudice, and discrimination create adverse social environment that may cause mental health problems (Meyer 2003). Members of sexual minority groups, especially gay men, are known to have a greater risk for mood disorders, depression, and anxiety disorders in comparison to heterosexuals (Bostwick et al. 2010; Hatzenbuehler et al. 2010; Shenkman and Shmotkin 2010). Most gay and bisexual men experience emotional and/or physical scarring throughout their developmental years in relation to their sexual orientation (Haldeman 2001; Shelton and Delgado-Romero 2011). Furthermore, as a sexual minority group, bisexual and gay men constantly cope with the impact of microaggressions, which are behaviors characterized by subtle, often innocuous messages that are condescendingly communicated to an attended target (Platt and Lenzen 2013; Shelton and Delgado-Romero 2011). Consequently, it is plausible that gay men may have an increased risk of developing a sex addiction as a means to cope with increased external stressors that may affect their mood/stress levels, similarly to Khantzian's (1997) "self-medication hypothesis" (Carnes 1992; Kaplan and Krueger 2010). However, further investigative research on a larger scale with more intervening variables is needed to assess the hypothesis.

The Five-Factor Model of personality traits were found to be independent of sexual addiction within the present study upon Israeli men. Personality was found to explain very minimal variance of HBYSAS risk groups and only low conscientiousness had a significant relationship with BYSAS risk groups. A possible explanation to the different results found in the Andreassen et al. (2018) study may be the exclusion of females in the present study, the difference between Norwegian and Israeli cultures, and/or the sample size (177 in the present study versus 23,533 in the Andreassen et al. (2018) study. In the literature, there appears to be a difference in congruence when comparing males and females between factors in the factor analysis of the Revised NEO-Personality Inventory (NEO-PI-R)(Montag and Levin 1994). Montag and Levin (1994) found Israeli male data to be less clear cut, and only moderately congruent with male American counterparts, whereas the combined male and female sample again showed high congruence in their coefficients. Similarly, sex differences between the FFM of personality traits have consistently been reported and the cultural differences have been widely assessed (Schmitt et al. 2008).

It appears that in contemporary society, scholars are reconceptualizing what "excessive sexual behavior" is, and that the components model of behavioral addiction (Griffiths 2005) fits well with the addictive qualities of such behaviors. Furthermore, the BYSAS has been conceptualized, constructed, validated, and has been found to be a psychometrically sound tool (Andreassen et al. 2018). Nevertheless, it should be mentioned that in the present study, covariances emerged in the model. For instance, Item 4 (failure to reduce/loss of control) was related to Item 1 (preoccupation), and Item 3 (engage to escape affect) was related to Item 5 (irritated when thwarted). This may be attributable to differences in sample characteristics or language-related interpretation of the items of the scale. However, the translated Hebrew version (Appendix) showed both acceptable internal consistency and excellent model fit indices. The six criteria to assess the risk for sexual addiction in the present study are based upon prior research of Andreassen et al. (2018) and may contribute to cumulative data in attaining well-defined diagnostic criteria for sex addiction. Consequently, the Hebrew BYSAS 
may stimulate further research in the field because it is a brief and easy-to-administer and easyto-score instrument.

The present study's main strength is in the testing of sexual orientation/identity rather than behaviors, because the former provides more information to the researcher than an individual's amount or form of sexual activity. Also, the study ensures a more precise and respectful measurement of one's sexual identity within minority groups than categorizing participants as either MSW (men who have sex with women) versus MSM. It is recognized that the present study cannot account for the processes that contribute to gay men's predominance in the high risk for sexual addiction group. However, the study's purpose was to explore whether there is a difference in sex addiction risk across sexual orientations. Further research should be carried out in the field to further identify the complexity of the factors associated with gay men being at higher risk for sexual addiction than heterosexuals or bisexuals.

\section{Limitations}

The present study is limited by the common shortcomings encountered in the psychological literature, including volunteerism (i.e., use of a self-selected sample) and use of self-report data. Also, the sample size was relatively small and comprised a disproportionate number of participants in the bisexual men subgroup. The finding that no bisexual participants were categorized as high risk was unexpected and suggests the need for replication with a more representative sample. A larger sample and less disproportional categories of sexual orientations may produce more robust results. Furthermore, due to the cross-sectional nature of the study, no cause-and-effect relationships can be made. Additionally, since the study was conducted with Israeli men only, cross-cultural generalizability cannot be made, but the robustness of the results may motivate follow-up research in other nations and/or cultures. Finally, while the HBYSAS showed excellent model fit and adequate reliability, its content validity, congruence, and test-retest reliability should be tested on a larger sample that also includes women. The preliminary findings presented here should provide an incentive for such research undertaking.

\section{Conclusions}

For the first time in the academic literature, the present study shows that the risk for sexual addiction differs across men with different sexual orientations. It cannot be established whether these findings are limited to Israeli men only, or to men in general, because no similar research results have been reported to date. Another important contribution of the work is the preliminary psychometric validation of the BYSAS in Hebrew, which showed excellent model fit and adequate internal reliability, suggesting that while the instrument needs to be further tested psychometrically, it may become a promising instrument in future Israeli sex addiction research.

Funding This study was supported by the Hungarian National Research, Development and Innovation Office (Grant number: KKP126835).

\section{Compliance with Ethical Standards}


Conflict of Interest The authors declare that they do not have any interests that could constitute a real, potential or apparent conflict of interest with respect to their involvement in the publication. The authors also declare that they do not have any financial or other relations (e.g. directorship, consultancy or speaker fee) with companies, trade associations, unions or groups (including civic associations and public interest groups) that may gain or lose financially from the results or conclusions in the study. Sources of funding are acknowledged.

Ethical Approval All procedures performed in this study involving human participants were in accordance with the ethical standards of University's Research Ethics Board and with the 1975 Helsinki Declaration.

Informed Consent Informed consent was obtained from all participants.

\section{Appendix}

שאלון התמכרות מינית ע"ש בירגין ייל (HBYSAS)

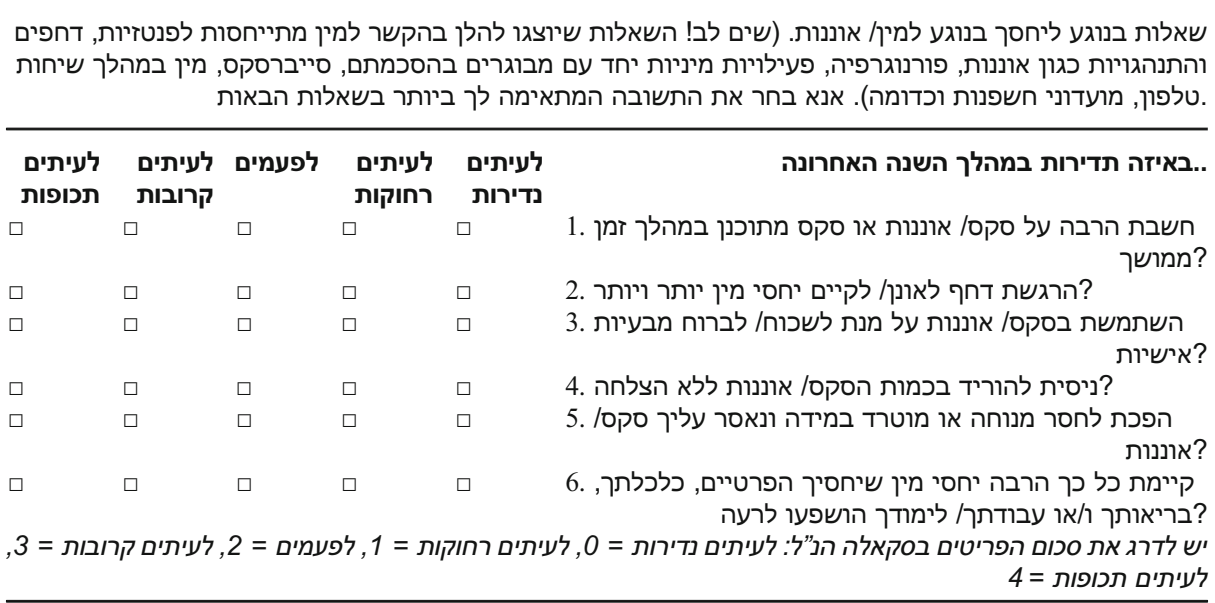

Open Access This article is distributed under the terms of the Creative Commons Attribution 4.0 International License (http://creativecommons.org/licenses/by/4.0/), which permits unrestricted use, distribution, and reproduction in any medium, provided you give appropriate credit to the original author(s) and the source, provide a link to the Creative Commons license, and indicate if changes were made.

\section{References}

American Psychological Association. (2002). Ethical principles of psychologists and code of conduct (2002). American Psychologist, 57(12), 1060-1073. https://doi.org/10.1037/0003-066X.57.12.1060.

Andreassen, C. S., Pallesen, S., Griffiths, M. D., Torsheim, T., \& Sinha, R. (2018). The development and validation of the Bergen-Yale sex addiction scale with a large national sample. Frontiers in Psychology, 9, 144. https://doi.org/10.3389/fpsyg.2018.00144.

Barrilleaux, J. C. (2016). Sexual addiction: Definitions and interventions. Journal of Social Work Practice in the Addictions, 16(4), 421-438. https://doi.org/10.1080/1533256X.2016.1235425 . 
Beaton, D. E., Bombardier, C., Guillemin, F., \& Ferraz, M. B. (2000). Guidelines for the process of cross-cultural adaptation of self-report measures. Spine, 25(24), 3186-3191. https://doi.org/10.1097/00007632200012150-00014.

Birchard, T. (2011). Sexual addiction and the paraphilias. Sexual Addiction and Compulsivity, 18(3), $157-187$. https://doi.org/10.1080/10720162.2011.606674.

Black, D. W., Kehrberg, L. L., Flumerfelt, D. L., \& Schlosser, S. S. (1997). Characteristics of 36 subjects reporting compulsive sexual behavior. American Journal of Psychiatry, 154(2), 243-249. https://doi. org/10.1176/ajp.154.2.243.

Bostwick, W. B., Boyd, C. J., \& Hughes, T. L. (2010). Dimensions of sexual orientation and the prevalence of mood and anxiety disorders in the United States. American Journal of Public Health, 100(3), 468-475. https://doi.org/10.2105/AJPH.2008.152942.

Bőthe, B., Bartók, R., Tóth-Király, I., Reid, R. C., Griffiths, M. D., Demetrovics, Z., \& Orosz, G. (2018). Hypersexuality, gender, and sexual orientation: A large-scale psychometric survey study. Archives of Sexual Behavior, 47(8), 2265-2276. https://doi.org/10.1007/s10508-018-1201-z .

Butler, A. C. (2000). Trends in same-gender sexual partnering, 1988-1998. Journal of Sex Research, 37(4), 333343. https://doi.org/10.1080/00224490009552056.

Carnes, P. (1992). Out of the shadows: Understanding sexual addiction. Center City, MN: Hazelden Publishing.

Chatzittofis, A., Savard, J., Arver, S., Öberg, K. G., Hallberg, J., Nordström, P., \& Jokinen, J. (2017). Interpersonal violence, early life adversity, and suicidal behavior in hypersexual men. Journal of Behavioral Addictions, 6(2), 187-193. https://doi.org/10.1556/2006.6.2017.027.

Cochran, S., Mays, V., \& Greer Sullivan, J. (2003). Prevalence of mental disorders, psychological distress, and mental services use among lesbian, gay, and bisexual adults in the United States. Journal of Consulting and Clinical Psychology, 71, 53-61. https://doi.org/10.1037/0022-006X.71.1.53.

Coleman, E., Horvath, K. J., Miner, M., Ross, M. W., Oakes, M., Rosser, B. R. S., \& Men's INTernet Sex (MINTS-II) Team. (2010). Compulsive sexual behavior and risk for unsafe sex among internet using men who have sex with men. Archives of Sexual Behavior, 39, 1045-1053. https://doi.org/10.1007/s10508-0099507-5.

Dhuffar, M. K., \& Griffiths, M. D. (2015). A systematic review of online sex addiction and clinical treatments using CONSORT evaluation. Current Addiction Reports, 2(2), 163-174. https://doi.org/10.1007/s40429015-0055-x.

Donnellan, M. B., Oswald, F. L., Baird, B. M., \& Lucas, R. E. (2006). The mini-IPIP scales: tiny-yet-effective measures of the big five factors of personality. Psychological Assessment, 18(2), 192-203. https://doi. org/10.1037/1040-3590.18.2.192.

Ethical Principles of Psychologists and Code of Conduct (2002). American Psychologist, 57(12), 1060-1073. https://doi.org/10.1037/0003-066X.57.12.1060 .

Gao, T., Xiang, Y. T., Zhang, H., Zhang, Z., \& Mei, S. (2017). Neuroticism and quality of life: Multiple mediating effects of smartphone addiction and depression. Psychiatry Research, 258, 457-461. https://oi. org/10.1016/j.psychres.2017.08.074.

Glick, S. N., Morris, M., Foxman, B., Aral, S. O., Manhart, L. E., Holmes, K. K., \& Golden, M. R. (2012). A comparison of sexual behavior patterns among men who have sex with men and heterosexual men and women. JAIDS Journal of Acquired Immune Deficiency Syndromes, 60(1), 83-90. https://doi.org/10.1097 /QAI.0b013e318247925e.

Gola, M., \& Potenza, M. N. (2018). Promoting educational, classification, treatment, and policy initiatives. Journal of Behavioral Addictions, 7(2), 208-210. https://doi.org/10.1556/2006.7.2018.51.

Green, B. A., Carnes, S., Carnes, P. J., \& Weinman, E. A. (2012). Cybersex addiction patterns in a clinical sample of homosexual, heterosexual, and bisexual men and women. Sexual Addiction \& Compulsivity, 19(1-2), 7798. https://doi.org/10.1080/10720162.2012.658343.

Griffiths, M. (1996). Nicotine, tobacco and addiction. Nature, 384(6604), 18-18. https://doi.org/10.1038/384018 $\mathrm{a} 0$.

Griffiths, M. (2005). A "components" model of addiction within a biopsychosocial framework. Journal of Substance Use, 10(4), 191-197. https://doi.org/10.1080/14659890500114359.

Grov, C., Parsons, J. T., \& Bimbi, D. S. (2010). Sexual compulsivity and sexual risk in gay and bisexual men. Archives of Sexual Behavior, 39(4), 940-949. https://doi.org/10.1007/s10508-009-9483-9.

Haldeman, D. C. (2001). Psychotherapy with gay and bisexual men. In G. R. Brooks \& G. E. Good (Eds.), The new handbook of psychotherapy and counseling with men: A comprehensive guide to settings, problems, and treatment approaches (2nd ed., pp. 796-815). San Francisco, CA: Jossey-Bass.

Hatzenbuehler, M. L., Hilt, L. M., \& Nolen-Hoeksema, S. (2010). Gender, sexual orientation, and vulnerability to depression. In Handbook of gender research in psychology (pp. 133-151). New York, NY: Springer. https://doi.org/10.1007/978-1-4419-1467-5_7. 
Herek, G. M., \& Garnets, L. D. (2007). Sexual orientation and mental health. Annual Review of Clinical Psychology, 3, 353-375. https://doi.org/10.1146/annurev.clinpsy.3.022806.091510.

IBM Corporation. (2017a). IBM Amos. Chicago: IBM SPSS.

IBM Corporation. (2017b). IBM SPSS statistics for Windows. Armonk, NY: IBM Corp.

Joannides, P. (2012). The challenging landscape of problematic sexual behaviors, including "sexual addiction" and "hypersexuality.". In P. J. Kleinplatz (Ed.), New directions in sex therapy: Innovations and alternatives (pp. 69-83). Philadelphia: Brunner Routledge.

Kafka, M. P. (2013). The development and evolution of the criteria for a newly proposed diagnosis for DSM-5: Hypersexual disorder. Sexual Addiction and Compulsivity, 20(1-2), 19-26. https://doi.org/10.1080 /10720162.2013.768127.

Kaplan, M. S., \& Krueger, R. B. (2010). Diagnosis, assessment, and treatment of hypersexuality. Journal of Sex Research, 47(2-3), 181-198. https://doi.org/10.1080/00224491003592863.

Karila, L., Wery, A., Weinstein, A., Cottencin, O., Petit, A., Reynaud, M., \& Billieux, J. (2014). Sexual addiction or hypersexual disorder: Different terms for the same problem? A review of the literature. Current Pharmaceutical Design, 20(25), 4012-4020. https://doi.org/10.2174/13816128113199990619.

Karim, R., \& Chaudhri, P. (2012). Behavioral addictions: An overview. Journal of Psychoactive Drugs, 44(1), 517. https://doi.org/10.1080/02791072.2012.662859 .

Kayiș, A. R., Satici, S. A., Yilmaz, M. F., Șimșek, D., Ceyhan, E., \& Bakioğlu, F. (2016). Big five-personality trait and internet addiction: A meta-analytic review. Computers in Human Behavior, 63, 35-40. https://oi. org/10.1016/j.chb.2016.05.012 .

Kelly, B. C., Bimbi, D. S., Nanin, J. E., Izienicki, H., \& Parsons, J. T. (2009). Sexual compulsivity and sexual behaviors among gay and bisexual men and lesbian and bisexual women. Journal of Sex Research, 46(4), 301-308. https://doi.org/10.1080/00224490802666225.

Khantzian, E. (1997). The self-medication hypothesis of substance use disorders: A reconsideration and recent applications. Harvard Review of Psychiatry, 4, 231-244. https://doi.org/10.3109/10673229709030550 .

Lemmens, J. S., Valkenburg, P. M., \& Peter, J. (2009). Development and validation of a game addiction scale for adolescents. Media Psychology, 12(1), 77-95. https://doi.org/10.1080/15213260802669458.

Levin, E. M., Koopman, J. S., Aral, S. O., Holmes, K. K., \& Foxman, B. (2009). Characteristics of men who have sex with men and women and women who have sex with women and men: results from the 2003 Seattle sex survey. Sexually Transmitted Diseases, 36(9), 541-546. https://doi.org/10.1097/OLQ.0b013e3181a819db.

Levy, I., Mor, Z., Anis, E., Maayan, S., Leshem, E., Pollack, S., ... Grossman, Z. (2011). Men who have sex with men, risk behavior, and HIV infection: Integrative analysis of clinical, epidemiological, and laboratory databases, 1243, 1363-1370. https://doi.org/10.1093/cid/cir244

McCrae, R. R. (1990). How well is openness represented in natural languages? European Journal of Personality, 4, 119-129.

McCrae, R. R., \& Costa, P. T. (1999). The big five trait taxonomy: History, measurement, and theoretical perspectives. In O. P. John \& S. Srivastava (Eds.), Handbook of personality: Theory and research (Vol. 2) (pp. 102-138). London: Guilford Publications https://doi.org/citeulike-article-id:3488537 . Accessed 18 July 2019.

McCrae, R. R., \& John, O. P. (1992). An introduction to the five-factor model and its applications. Journal of Personality, 60(2), 175-215. https://doi.org/10.1111/j.1467-6494.1992.tb00970.x.

Mcghee, R. L., Ehrler, D. J., Buckhalt, J. A., \& Phillips, C. (2012). The relation between five-factor personality traits and risk- taking behavior in preadolescents. Scientific Research, 3(8), 558-561. https://doi.org/10.4236 /psych.2012.38083.

Mehroof, M., \& Griffiths, M. D. (2010). Online gaming addiction: the role of sensation seeking, self-control, neuroticism, aggression, state anxiety, and trait anxiety. Cyberpsychology, Behavior and Social Networking, 13(3), 313-316. https://doi.org/10.1089/cyber.2009.0229.

Meyer, I. H. (2003). Prejudice, social stress, and mental health in lesbian, gay, and bisexual populations: conceptual issues and research evidence. Psychological Bulletin, 129(5), 674-697. https://doi.org/10.1037 /0033-2909.129.5.674.

Missildine, W., Feldstein, G., Punzalan, J. C., \& Parsons, J. T. (2005). S/he loves me, s/he loves me not: Questioning heterosexist assumptions of gender differences for romantic and sexually motivated behaviors. Sexual Addiction \& Compulsivity, 12(1), 65-74. https://doi.org/10.1080/10720160590933662 .

Montag, I., \& Levin, J. (1994). The five-factor personality model in applied settings. European Journal of Personality, 8(1), 1-11. https://doi.org/10.1002/per.2410080102.

Oreg, S., \& Sverdlik, N. (2014). Source personality and persuasiveness: Big five predispositions to being persuasive and the role of message involvement. Journal of Personality, 82(3), 250-264. https:/doi. org/10.1111/jopy.12049 .

Orford, J. (2001). Excessive appetites: A psychological view of addictions (2nd ed.). New York: John Wiley \& Sons Ltd.. 
Parsons, J. T., Kelly, B. C., Bimbi, D. S., DiMaria, L., Wainberg, M. L., \& Morgenstern, J. (2008). Explanations for the origins of sexual compulsivity among gay and bisexual men. Archives of Sexual Behavior, 37(5), 817-826. https://doi.org/10.1007/s10508-007-9218-8.

Pinto, J., Carvalho, J., \& Nobre, P. J. (2013). The relationship between the FFM personality traits, state psychopathology, and sexual compulsivity in a sample of male college students. The Journal of Sexual Medicine, 10(7), 1773-1782. https://doi.org/10.1111/jsm.12185.

Platt, L. F., \& Lenzen, A. L. (2013). Sexual orientation microaggressions and the experience of sexual minorities. Journal of Homosexuality, 60(7), 1011-1034. https://doi.org/10.1080/00918369.2013.774878.

Qualtrics. (2005). Qualtrics. Utah: Provo Retrieved from https://www.qualtrics.com. Accessed 18 July 2019.

Raviv, M. (1993). Personality characteristics of sexual addicts and pathological gamblers. Journal of Gambling Studies, 9(1), 17-30. https://doi.org/10.1007/BF01019922.

Raynor, D. A., \& Levine, H. (2009). Associations between the five-factor model of personality and health behaviors among college students. Journal of American College Health, 58(1), 73-81. https://doi. org/10.3200/JACH.58.1.73-82.

Rickham, P. P. (1964). Human experimentation. Code of ethics of the World Medical Association. Declaration of Helsinki. British Medical Journal, 2(5402), 177 Retrieved from http://www.ncbi.nlm.nih. gov/pubmed/14150898. Accessed 18 July 2019.

Rinehart, N. J., \& McCabe, M. P. (1997). Hypersexuality: Psychopathology or normal variant of sexuality? Sexual and Marital Therapy, 12(1), 45-60. https://doi.org/10.1080/02674659708408201 .

Rooney, B. M., Tulloch, T. G., \& Blashill, A. J. (2018). Psychosocial syndemic correlates of sexual compulsivity among men who have sex with men: A meta-analysis. Archives of Sexual Behavior, 47(1), 75-93. https://doi.org/10.1007/s10508-017-1032-3 .

Schmitt, D. P., Realo, A., Voracek, M., \& Allik, J. (2008). Why can’t a man be more like a woman? Sex differences in big five personality traits across 55 cultures. Journal of Personality and Social Psychology, 94(1), 168-182. https://doi.org/10.1037/0022-3514.94.1.168.

Shelton, K., \& Delgado-Romero, E. A. (2011). Sexual orientation microaggressions: the experience of lesbian, gay, bisexual, and queer clients in psychotherapy. Journal of Counseling Psychology, 58(2), 210-221. https://doi.org/10.1037/a0022251.

Shenkman, G., \& Shmotkin, D. (2010). Mental health among Israeli homosexual adolescents and young adults. Journal of Homosexuality, 58(1), 97-116. https://doi.org/10.1080/00918369.2011.533630.

Statistics, C. B. (2018). Average wages per employee job of Israeli workers in June 2018. Jerusalem. Retrieved from http://www.cbs.gov.il/reader/newhodaot/hodaa_template.html?hodaa=201826267. Accessed 18 July 2019.

Sussman, S., Lisha, N., \& Griffiths, M. (2011). Prevalence of the addictions: A problem of the majority or the minority? Evaluation \& the Health Professions, 34(1), 3-56. https://oi.org/10.1177/0163278710380124.

Terracciano, A., \& Costa, P. T. (2004). Smoking and the five-factor model of personality. Addiction, 99(4), 472481. https://doi.org/10.1111/j.1360-0443.2004.00687.x.

Terracciano, A., Löckenhoff, C. E., Crum, R. M., Bienvenu, O. J., \& Costa, P. T. (2008). Five-factor model personality profiles of drug users. BMC Psychiatry, 8(1), 22. https://doi.org/10.1186/1471-244X-8-22.

Wang, J., Dey, M., Soldati, L., Weiss, M. G., Gmel, G., \& Mohler-Kuo, M. (2014). Psychiatric disorders, suicidality, and personality among young men by sexual orientation. European Psychiatry, 29(8), 514-522. https://doi.org/10.1016/j.eurpsy.2014.05.001.

WHO. (2018). Seventy-first world health assembly progress report (20.3 ed.). Geneva: World Health Organization.

Wilcox, C. (2015). Sex and pornography addictions. San Diego: Reference Point Press.

Young, R. M., \& Meyer, I. H. (2005). The trouble with "MSM" and "WSW": erasure of the sexual-minority person in public health discourse. American Journal of Public Health, 95(7), 1144-1149. https:/doi. org/10.2105/AJPH.2004.046714.

Zilberman, N., Yadid, G., Efrati, Y., Neumark, Y., \& Rassovsky, Y. (2018). Personality profiles of substance and behavioral addictions. Addictive Behaviors, 82, 174-181. https://doi.org/10.1016/j.addbeh.2018.03.007.

Publisher's Note Springer Nature remains neutral with regard to jurisdictional claims in published maps and institutional affiliations. 